\title{
Ex Situ Bioremediation of Contaminated Soils: An Overview of Conventional and Innovative Technologies
}

\author{
M. CONCETTA TOMEI ${ }^{1}$ and ANDREW J. DAUGULIS ${ }^{2}$ \\ ${ }^{1}$ Water Research Institute, C.N.R, Rome, Italy \\ ${ }^{2}$ Department of Chemical Engineering, Queen's University, Kingston, Ontario, Canada
}

\begin{abstract}
Bioremediation as a sustainable alternative to chemical-physical processes is an attractive solution for soil decontamination and renewal of polluted sites. Depending on the site characteristics and target treatment requirements for the decontaminated soil, in situ or ex situ technologies are employed. Ex situ technologies are advantageous when a safe and effective intervention is required (i.e., in the presence of severe contamination of highly hazardous compounds). In this review, conventional and innovative ex situ technologies for soil bioremediation are presented. For each one the principle of operation and recent applications are reported. In addition, strategies to improve their efficiency are explored. Finally, the possibility of making these technologies more competitive by indicating research needs for their future development is highlighted.
\end{abstract}

KEY WORDS: composting, ex situ technologies, landfarming, slurry bioreactors, soil bioremediation, two-phase partitioning bioreactors

\section{INTRODUCTION}

The contamination of soil arising from industrial activity, high intensity farming, and poor landfill disposal practices has historically occurred without adequate regard for their lasting environmental legacy. Increased awareness

Address correspondence to M. Concetta Tomei, Water Research Institute, C.N.R., Via Salaria km 29,300 C.P. 10, 00015 Monterotondo Stazione (Rome), Italy. E-mail: tomei@irsa.cnr. it 
of the limited availability of high quality land and associated natural resources has increased interest in environmental protection as a means of safeguarding human health and, in this context, the decontamination and renewal of polluted sites has become a priority.

This has, as a consequence, stimulated research and development activities aimed at generating efficient and cost-effective methods for the remediation of contaminated sites. Initial approaches to decontaminating sites involved removing the contaminated soil and transporting it to landfills to segregate the contaminated material. This approach is fraught because it is not actually a treatment method, and merely transfers the pollution from one site to another. Additionally, this approach can in fact exacerbate the problem, with possible spreading of contamination during excavation, manipulation and transfer of the material. As well, segregation in a landfill may not be an ultimate solution as careful monitoring and control of the site is required for many years.

A definitive, if more complex solution to the remediation of contaminated soil is the destruction or degradation of the contaminants to give harmless products, which can be achieved by chemical-physical processes (i.e., chemical oxidation, base catalyzed dechlorination, UV oxidation), thermal processes (i.e., incineration), or biological degradation. This last option, defined as bioremediation, is considered very promising in that natural biological activity is utilized to partially degrade the contaminants to less harmful products or, in the most favorable case, to completely mineralize them. The utilization of natural agents (i.e., bacteria, fungi, and plants) as catalysts makes bioremediation more environmentally sustainable in comparison with the other treatment methods. Bioremediation can be considered to be an application of Green Engineering that, according to Kirchhoff, ${ }^{1}$ is based on "the design, commercialization and use of processes and products that are feasible and economical while minimizing pollution at the source and risk to human health and the environment" (p. 5349). These features have increased interest in bioremediation, which has been extensively investigated in recent years, with a significant level of application being reported.

In addition to enhanced sustainability which generally has good public acceptance, other advantages of bioremediation are the possibility of on site application, low cost and low technology requirements that make implementation easier, the potential for a conclusive solution of the soil contamination problem, and the possibility of being coupled with other chemical or physical processes thereby increasing the efficiency and the spectrum of applications. On the other hand, bioremediation does have several limiting aspects that are currently subjects of research activity. For example, there are some classes of contaminants (i.e., chlorinated organic compounds, pesticides) that are difficult to degrade biologically and are often toxic to the microbial agents employed, ${ }^{2}$ thus requiring specifically acclimatized microbial populations and long reaction times to reach adequate remediation levels. Moreover, during 
the biodegradation of complex molecules metabolites can be produced that are even more toxic than the initial compound and can inhibit the bacterial population. This has been found for instance in the biodegradation of polycyclic aromatic hydrocarbons (PAHs), ${ }^{3}$ and of heavy hydrocarbons, as well as in the bioremediation of diesel-contaminated soil ${ }^{4}$ and pesticides. ${ }^{5}$

Finally, as for all biological processes, bioremediation is case (site)specific, in that the optimal operating conditions may not have general validity and can be extrapolated to other cases only with caution. The implementation of a bioremediation process is therefore not entirely straightforward, and preliminary treatability experiments are necessary to define an appropriate microbial population and the best operating conditions to be used.

Microorganisms are the most widely used biocatalysts for soil remediation due to their capacity for adaptation to the often severe environmental conditions (complexity of the soil matrix, inadequate amounts of noncarbon nutrients, extremes of temperature, $\mathrm{pH}$, and moisture content) present in sites. Advantageously, however, indigenous microorganisms can often be isolated from the soil to be treated, and this is certainly an advantage for shortening the adaptation process. Bioremediation processes have been conducted under both aerobic and anaerobic conditions, although aerobic conditions are the most common. A simple classification proposed by Vidali $^{6}$ of the main groups of microorganisms effective in bioremediation of important classes of compounds is reported in Table 1. Bioremediation can be performed via metabolic (the pollutant is used as sole source of carbon and energy) or cometabolic pathways (an additional substrate is necessary as a source of carbon and energy to sustain growth) and a wide range of compounds have been investigated with different biocatalysts.

\subsection{Why and When Ex Situ Technologies?}

Bioremediation techniques can be classified into two broad categories, in situ and ex-situ methods, depending on the soil to be handled and the application location. For in situ methods the treatment is applied directly to the soil without excavation and transport. This approach has the significant advantage of avoiding contaminant spreading which can occur during transport, and is relatively simple to apply. In situ processes are applied to the contaminated soil, and minimal technological equipment is required for the addition of air, nutrients and/or microorganisms (indigenous or exogenous). The main limitations of this approach include the depth of soil that can be reached by oxygen (due to diffusion resistances), which is generally limited to the superficial layer (average value of $30 \mathrm{~cm}$ from the surface), and the slow kinetics resulting in extended treatment times to complete the biodegradation process. In addition, in situ processes are uncontrolled, making it difficult to predict the extent of remediation of the contaminated 
TABLE 1. Classification of microorganisms employed in soil bioremediation processes, ${ }^{6}$ metabolic pathway, and recent literature data on their application. PAHs = Polycyclic Aromatic Hydrocarbons, PCBs $=$ Polychlorinated Biphenyls.

\begin{tabular}{lllc}
\hline Microorganisms & \multicolumn{1}{c}{ Metabolism } & \multicolumn{1}{c}{ Effective for } & References \\
\hline Aerobic & Metabolic & Pesticides & 7 \\
& & $\begin{array}{l}\text { Hydrocarbons } \\
\text { (both alkanes and PAHs) }\end{array}$ & 8,9 \\
& & PAHs & $10,11,12$ \\
& Cometabolic & Herbicides & 13 \\
& & PAHs & 14 \\
Anaerobic & Explosives & 15,16 \\
& & PCBs & 17 \\
& & Chlorinated solvents & 18 \\
Fungal biomass & Herbicides & 13 \\
& Cometabolic & Pesticides & 19 \\
& Metabolic & PCBs & 17 \\
& & PAHs & 20,21 \\
& Cometabolic & Pesticides & 22 \\
Methylotrophs & Biosorption & Organochlorines & 23 \\
& Cometabolic: methane is & Dyes & Chlorinated aliphatic, \\
& the source of carbon & trichloroethylene & 6 \\
& and energy & 1,3-dichloroethane & \\
\hline
\end{tabular}

Note. For metabolic, the contaminant is the sole source of carbon and energy. For cometabolic, the contaminant is not used as the sole source of carbon and energy and an additional substrate is necessary to sustain the microbial growth.

site; the operational strategy is to monitor the level of pollution with time, which can also be quite challenging depending on the characteristics of the soil. Consequently, in situ bioremediation techniques are cost efficient but not generally applicable especially in cases of severe contamination and/or when rapid intervention strategies are required.

Under these circumstances ex situ technologies can offer an advantageous alternative. Within the definition of ex situ quite a wide spectrum of technologies exist, which are characterized by different degrees of complexity, although their common feature is the treatment of excavated soil. This is in principle a disadvantage due to the associated additional cost, and the risk related to the possible dispersion of the contamination during excavation, and transport. The latter risk is, in many cases, limited by undertaking the treatment on site with a treatment facility located in the area of interest. On the other hand, there are several advantages that make ex situ technologies competitive, the most important being the possibility of better controlling the remediation process (even with the simplest technological solutions; i.e., biopiles) because the contained reaction environment is more manageable and the treatment process is more predictable than an in situ environment. As a consequence, it is possible to increase the biodegradation kinetics, optimize the operating parameters, enhance mass transfer, and provide additional pretreatments to enhance the process efficiency. These features are 
more relevant for bioreactors that can be operated and controlled as industrial bioprocesses, but with higher costs in comparison to simpler ex situ solutions.

Back to the questions:

1. Why ex situ technologies? The answer is in the predictability and high efficiency of ex situ bioremediation technologies that are critical in terms of effectively reducing environmental and human health risks;

2. When ex situ technologies? The first priority is when a safe and effective intervention is required (in the presence of severe contamination of highly hazardous compounds). Second, when a high degree of treatment is required, when the contaminated area is easily accessible for excavation, and when the contamination is concentrated in the superficial soil layer.

In this review conventional and innovative ex situ technologies for soil bioremediation are presented. For each one a short description of the principle of operation and recent applications, mainly focusing on the last five years, are reported. In addition, strategies to improve their efficiency are explored. The objective of the paper is also to highlight the possibility of making these technologies more competitive by indicating research needs for their future development.

\section{STRATEGIES TO IMPROVE BIOREMEDIATION EFFICIENCY}

The efficiency of soil bioremediation is strongly influenced by the characteristics of the soil matrix, which is case (site)-specific; therefore, independent of the applied technology an accurate physical characterization is required for the development of an effective intervention plan. The main physical characteristics of relevance are porosity, density, and air permeability ${ }^{25}$ due to their important influences on the mass transport and distribution ${ }^{26}$ in the solid matrix of substrates, oxygen, and nutrients. The relevance of porosity and pore size distribution as an important characterizing element of soil structure was highlighted by Caravaca and Roldan, ${ }^{27}$ who suggested the micromorphometric method, based on image analysis of soil thin sections, as a means of supplying useful information about the complexity of pore patterns in soil, pore shape and the relative positions of the aggregates and pores.

In addition to a preliminary accurate characterization, there are general strategies that can be applied especially with the most highly engineered technological solutions (i.e., contained vessel composting, bioreactors) to enhance soil bioremediation performance. Several different principles of operation are possible: enhancement of biological reactions via bioaugmentation 
and biostimulation, increase of biodegradability by thermal or oxidizing pretreatment, and solvent extraction (i.e., pollutant transfer from the soil to a liquid phase) to improve the accessibility of the contaminant by the microorganisms. A short summary of the various approaches is provided in the following paragraphs followed by a more detailed description of the technologies.

\subsection{Bioaugmentation}

In the natural or default form of soil bioremediation, the existing native microflora already present in the polluted soil are used to degrade the target contaminant(s). However, in situations in which microbial populations do not exist in adequate numbers to efficiently degrade the target compounds, inoculation of enriched/acclimated consortia or strains is provided. ${ }^{28}$ This operation is called bioaugmentation. Addition of pure strains has been applied primarily in lab scale studies and has not been successful in full-scale situations due to the competition with autochthonous species. Therefore mixed cultures with a large variety of microorganisms are utilized in practice. ${ }^{29}$ Different sources and types of biomass have been utilized, including fungi, ${ }^{20,21,23,30}$ anaerobic and aerobic sludge, ${ }^{14}$ and compost. ${ }^{31,32}$

Conflicting results ${ }^{33,34}$ have been reported on the effectiveness of bioaugmentation strategies in the bioremediation of liquid and solid matrices. Successful application is more difficult in a complex and dynamic matrix such as soil where many abiotic and biotic factors affect the survival and activity of the inoculated microorganisms. ${ }^{34}$ The abiotic factors include fluctuations in temperature, humidity level, $\mathrm{pH}$, nutrient content, and availability. Biotic factors are more relevant as demonstrated by the easier growth of added microorganisms to sterile soil. ${ }^{33}$ The main adverse effects are the already mentioned competition with autochthonous microorganisms for substrates and nutrients, the predation by protozoa and bacteriophages, and the presence of roots that release organic compounds thereby altering the growth environment. Finally, the heterogeneity of the soil matrix can make homogeneous delivery of the added inocula difficult. As a consequence, in order to increase the probability of success of bioaugmentation it is a priority to apply operating strategies aimed at improving the survival and long-term efficiency of the inoculated species. El Fantroussi and Agathos ${ }^{33}$ suggested intervention in terms of microbial selectivity (that is by adding species able to grow in a metabolic niche not utilized by the indigenous microbiota) and with physical protection systems for the added species (i.e., through encapsulation or favoring biofilm growth).

\subsection{Biostimulation}

Biostimulation consists of the addition of appropriate nutrients (nitrogen, phosphorus, trace elements) to provide the microorganisms with a reaction environment favorable to the development of metabolic pathways for 
contaminant biodegradation. Nitrates and phosphates ${ }^{35}$ and fertilizers were successfully used as biostimulating agents in the bioremediation of PAHs. ${ }^{36}$ Another biostimulation strategy is the addition of easily biodegradable substrates which act as primary substrates in a co-metabolic situation in which the pollutant is degraded as a secondary substrate but at acceptable rates. Biodiesel, ${ }^{37}$ municipal wastewater, ${ }^{38}$ oil refinery sludge, ${ }^{38}$ biosolids, ${ }^{14}$ sunflower oil, ${ }^{39}$ and chitosan ${ }^{40}$ have been utilized with positive effects in this capacity in PAH bioremediation.

Temperature can also play a positive role in biostimulation by increasing biomass activity (as is usefully applied in composting) but it is important to note that excessively high temperatures can increase the volatility of the contaminants with consequent increased risk of dispersion in the environment. It is important to note that temperature control is not an easy task in full-scale applications in even the simplest ex situ technologies such as landfarming and composting. More effective temperature control can be achieved only in more engineered systems such as contained vessel composting and slurry bioreactors but this implies a significant increase in the operating costs.

\subsection{Combined Bioaugmentation/Biostimulation}

A large spectrum of amendments as sources of microorganisms in bioaugmentation and of nutrients in biostimulation are reported in the two previous paragraphs, and some of them, such as activated sludge, biosolids, and compost are, at the same time, sources of bacteria and nutrients. This aspect makes it difficult to distinguish between the prevailing mechanisms (bioaugmentation or biostimulation) affecting the bioremediation process, and it can be assumed that a positive action of combined bioaugmentation/biostimulation takes place.

Advantages of the combined bioaugmentation/biostimulation strategies are highlighted in a recent review article ${ }^{41}$ reporting the limitations of the two single approaches and the possibility of obtaining improved complementary effects when combined.

Namkoong et al. ${ }^{42}$ utilized compost and activated sludge as amendments in the bioremediation of a diesel contaminated soil $(10 \mathrm{~g} / \mathrm{kg})$ and observed a significant improvement in the removal efficiencies ( $99 \%)$ for total hydrocarbons, for both amendments, with a soil:amendment ratio of 1:0.5 in comparison with the control test with the soil giving a removal of only $67 \%$. Also, Hamdi et al. ${ }^{31}$ successfully utilized a combined bioaugmentation/biostimulation strategy in the decontamination of PAH contaminated soil $(0.3 \mathrm{~g} / \mathrm{kg})$ by adding sewage sludge compost and decaying rice straw. In the latter case they achieved PAH removal efficiencies of $>96 \%$ for anthracene and pyrene in 120 days, which was significantly better in comparison to the percent removal observed of the unamended PAH-spiked soil (63\% and 33\% for anthracene and pyrene, respectively). 


\subsection{Chemical and Thermal Pretreatments}

For enhanced bioremediation performance pretreatment of the contaminated soil can be accomplished via chemical or thermal processes ${ }^{43}$ aimed at increasing the substrate bioavailability. The rate of biodegradation of contaminants in soil is negatively influenced by the slow desorption rate of the target molecules from the soil particles due to the slow diffusion of the compound through the pore liquid, and from the affinity of the contaminant to soil organic matter. Thermal treatment prior to microbial remediation can increase the rate of diffusion thereby increasing the mass transfer rate of contaminants in water and enhance their bioavailability. The same effect can be obtained with a chemical pretreatment by the addition of organic solvents or mobilizing agents, which increase the mass transfer rate of hydrophobic compounds in soil.

Water and single solvents or mixtures of solvents (ethanol, 2-propanol, acetone, 1-penthanol) were investigated with positive results in the remediation of $\mathrm{PAHs}^{44}$ and polychlorinated biphenyls $(\mathrm{PCBs})^{8}$ contaminated soils. The use of water immiscible and nonbiodegradable solvents is exploited in two-phase partitioning bioreactors (TPPBs), which have been recently proposed as an alternative technology to classical slurry phase bioreactors. In the case of TPPBs the solvent is characterized by a high affinity for the compound to be removed, and is thereby able to concentrate large amounts of substrate that are subsequently degraded in the two-phase bioreactor. TPPB technology is presented in detail later in this review.

Similar to organic solvents, surfactants may also facilitate the desorption of hydrophobic pollutants from the soil matrix and enhance their dispersion in the aqueous phase. Surfactants are classified as anionic, cationic and nonionic depending on the type of charged group and this characteristic determines their specificity for the contaminant to be removed.

Surfactants that have been utilized include both synthetic and biological ones, that is produced by microorganisms. ${ }^{45,46}$ There are many bacterial species that produce biosurfactants including Pseudomonas aeruginosa (mono- and di-rhamnolipid biosurfactants), Corynebacterium, Nocardia, and Rhodococcus spp. (phospholipids, trehalose dimycolates/dicorynomycolates, glycolipids) and Bacillus subtilis (surfactin). ${ }^{45,47}$ This feature can be profitably employed in soil bioremediation by inoculating the soil with a biosurfactant producing pure strain or favoring the development of indigenous biosurfactant producing bacteria found in uncontaminated and contaminated soil ${ }^{48}$ through optimization of the growth conditions. Also, amendments such as compost can be a source of biosurfactants, as reported by Montoneri et al., ${ }^{49}$ who found biosurfactants as a coproduct of composting. It is worth noting that the addition of external inocula of biosurfactant producing pure strains is a form of bioaugmentation, which could be affected by the uncertain 
long-term survival of the added species in soil. In addition, the provision of favorable growth conditions conducive to the proliferation of indigenous microorganisms able to produce biosurfactants may also be challenging. Microbial biosurfactant production is regulated by carbon and nitrogen levels present, and it has been found that nitrogen limitation has a stimulating effect in biosurfactant production by some microorganisms. ${ }^{45}$ This can have negative effects in soil bioremediation systems, however, in which nutrients are often added to enhance process performance (biostimulation). The optimization of the operating conditions for biosurfactant applications in soil bioremediation is still under investigation but the advantages in terms of improving process performance, biodegradability, and reduced toxicity make its utilization a promising alternative in comparison to synthetic additives. This is demonstrated by the latest advancements in this field which have been focused on the application of nontoxic biodegradable extracting agents as alternatives to organic solvents and synthetic surfactants. ${ }^{35,50-52}$ Cyclodextrins were utilized in the removal of $\mathrm{PAHs}^{53}$ and chlorinated hydrocarbons ${ }^{54}$ with satisfactory results and their performance was not affected by temperature in the range of $5-35^{\circ} \mathrm{C}$. Also biosurfactants and phytogenic surfactants (i.e., rhamnolipids and dissolved humic substances have been found effective in intensifying the bioremediation of PCB- and PAH-contaminated soils). ${ }^{54}$ Vegetable oil is another low-cost and nontoxic proposed alternative to organic solvents as an effective sorption medium for hydrophobic compounds. For example, Gong at al. ${ }^{39}$ obtained very high removal efficiencies (90\%) in PAH extraction from contaminated soil near a manufactured gas plant $(1.2 \mathrm{~g} / \mathrm{kg})$ with sunflower oil.

A commercial product, BioSolve (http://www.biosolve.com/applicat ions/soilremediation), a water-based, biodegradable surfactant, has been formulated to assist in the remediation of soil contaminated with hydrocarbons. The principle of operation of BioSolve consists of the microencapsulation of the hydrocarbons (through the formation of micelles), resulting in a multiple order of magnitude decrease in droplet size and a corresponding increase in the surface area accessible to bacteria. This transformation mobilizes the hydrocarbons and increases their bioavailability.

In using biodegradable extracting agents as a pretreatment prior to the bioremediation stage a critical concern is the possible competition of the agent with the pollutant as a carbon source for the microorganisms, with possible preferential degradation of the biosolvent/biosurfactant and consequent reduction in process efficiency.

Finally, chemical pretreatment can also be performed with an oxidizing agent to enhance the biodegradability of complex pollutants, with ozone being the most widely investigated reagent for this application. Its use was demonstrated effective for the bioremediation of PAHs and the process performance was improved in combination with soil washing. ${ }^{55}$ Ozonation as a pretreatment was also successfully applied to improve the performance 
of the bioremediation of recalcitrant compounds from long-term weathered crude oil contaminated soil. ${ }^{56}$ Alternative or complementary oxidizing agents to ozone have also been tested. Both ozone and Fenton's reagent were found effective in improving the aerobic biodegradation of creosote in pretreated sand and peat ${ }^{57}$ while Piskonen and Itävaara ${ }^{58}$ observed that the use of Fenton reagent significantly enhanced the mineralization of pyrene and phenanthrene, with an increase in efficiency of about $100 \%$ and $50 \%$, respectively.

The use of oxidative pretreatment must be tempered by two critical considerations, however: (a) the formation of intermediate compounds that can be toxic to the microorganisms performing the subsequent biodegradation step; and (b) the optimal dosage of the oxidant, which has to be high enough to provide an efficient pretreatment but not overdosed to avoid the oxidation of the biodegradable matter, which can be more economically removed in the biological step.

\section{CONVENTIONAL TECHNOLOGIES}

\subsection{Landfarming}

Landfarming is one of the most widely used soil remediation technologies, essentially for its low technological footprint and, consequently, low-cost characteristics. Landfarming is relatively simple to apply and consists of the excavation and placement of contaminated soils into lined beds. The liner comprises high-density polyethylene (HDPE) or other impermeable materials, necessary to avoid leachate infiltrations with consequent risk of groundwater contamination. To provide sufficient aeration to the contaminated soil, the beds are periodically tilled or turned over until the biodegradation process is completed to the required extent. The principle of operation consists of the stimulation of the indigenous population of microorganisms to aerobically degrade the contaminants.

Process performance can be optimized by adequate control of the operating parameters, ${ }^{59}$ which consist of the following:

- Moisture content: The optimal value is between $40 \%$ and $85 \%$ of the waterholding capacity of the soil. The range of values results from the need to ensure an adequate growth environment for the microorganisms and, at the same time, to avoid too high a moisture content that increases the diffusion resistances for oxygen transport to the microorganisms. Control is accomplished by simple irrigation or spraying equipment commonly used in agriculture practice.

- Aeration: Aeration is provided by periodically tilling the soil to ensure adequate mixing and the provision of oxygen. 
- pH: Optimal pH values for bacterial growth are in the range of 6-8, and the target value is generally controlled by adding low cost materials such as crushed limestone, agricultural lime, or elemental sulfur.

- Amendments: Different amending agents can be added depending on the soil characteristics. Soil bulking agents such as sawdust or straw are utilized to improve the solid texture and avoid soil clumping that can make it difficult to provide homogeneous aeration. Fertilizers can also be added to give the necessary nutrient dosage to maintain an optimal C:N:P (100:5:1) ratio.

The main advantage of landfarming is its use of simple equipment, and operability that makes the technology highly cost competitive.

Relevant aspects to be considered when applying landfarming are the production of leachate and the volatilization of the compounds from the contaminated soil. Depending on the nature of the placement site, a leachate collection and treatment system is required to prevent groundwater contamination. Moreover, the emission of volatile organic compounds (VOCs) from the landfarming area can result in air pollution problems and health risks for the workers. To reduce the impact of air emissions, the treatment area should be covered with a greenhouse structure capable of avoiding or minimizing dust and the volatilization of lighter compounds. The prevention of groundwater and air pollution increases treatment cost, thereby reducing the main advantage of the technology. Both groundwater and air pollution have been taken into account in the ever more stringent environmental regulations and this has caused a reduction in recent landfarming application after its extensive use in the 1960s. Additional constraints in applying landfarming include the requirement for large treatment areas, the slow microbial kinetics, and applicability limited to superficially contaminated soil (depth $10-40 \mathrm{~cm}$ ). ${ }^{59}$

Landfarming has been successfully used to treat soils contaminated with aliphatic and aromatic hydrocarbons, pesticides, creosote, and oily sludge from refineries, and it is still a valid technology when lengthy remediation times are not a critical concern, and the degree of contamination is not so high as to exert a strong inhibitory effect on the bacterial population. A recent application of landfarming to the bioremediation of soils heavily contaminated ( $>5 \mathrm{~g} / \mathrm{kg}$ ) with hexachlorocyclohexane $(\mathrm{HCH})$ isomers is reported by Rubinos et al. ${ }^{60}$ They found different behavior of the four investigated isomers: two of them, a and g, were significantly removed (89\% and $82 \%$ of the initial concentration in 350 days for the a and g respectively) while for the others ( $b$ and $d$ ) a negligible decrease was observed. This finding is a good example of the high specificity of the bioremediation method. In addition favorable performance was mainly dependent on the water content, optimal temperature $\left(10-40^{\circ} \mathrm{C}\right)$, and periodic tilling to favor the homogeneous distribution of the contaminants in the soil. 
Gallego et al. ${ }^{61}$ evaluated the applicability of landfarming to the remediation of weathered hydrocarbons in a soil contaminated with diverse and very old crude oil spills. In this condition, in principle, bioremediation is not a competitive alternative because, after a long period of time (of the order of decades in the case study), natural attenuation has caused the removal of the more easily degradable hydrocarbon fractions leaving the most bioresistant components behind. The authors undertook different landfarming strategies (watering, tilling, fertilizer and surfactant addition) and obtained the best results, $67 \%$ hydrocarbon reduction, for an initial concentration of $3 \mathrm{~g} / \mathrm{kg}$, after 150 days, in the plot treated with watering and tilling and the addition of a slow release fertilizer. The high removal efficiency obtained in the weathered soil is an effective demonstration of the good performance achievable with this simple technology, if adequately managed, with a particular biorefractory soil matrix.

Landfarming applications are also reported for severe climatic conditions where its easy applicability is an important added value. McCarthy et al. ${ }^{62}$ investigated landfarming with nutrient addition and frequent strong tilling to treat a soil moderately contaminated $(1.5-2 \mathrm{~g} / \mathrm{kg})$ with hydrocarbons located in Alaska (latitude $71.3^{\circ} \mathrm{N}$ ). Despite the cold temperatures (average monthly values $1.3-4.9^{\circ} \mathrm{C}$ ) the target soil clean up was achieved in the relatively short time of 4-8 weeks depending on the degree of contamination of the site area. Satisfactory results are also reported by Paudyn et al. ${ }^{63}$ for landfarming a application in a Canadian Arctic site (average summer temperature $3^{\circ} \mathrm{C}$ ) contaminated by diesel fuel $(\sim 3 \mathrm{~g} / \mathrm{kg})$. Different strategies of aeration and nutrient addition were compared to a control plot, resulting in the observation that the addition of a fertilizer was the most effective solution. It is worth noting the significant volatilization when rototilling is applied, as the rate of volatilization is of the same order as the bioremediation rate. This is a critical aspect to be considered in order to reduce the negative impact of soil treatment on human health.

An example of a landfarming application in an oppositely severe climatic condition is reported by Marin et al., ${ }^{64}$ who investigated the bioremediation of refinery sludge containing hydrocarbons $(5-6 \% \mathrm{w} / \mathrm{w})$ in semiarid conditions. In this case, landfarming consisted of depositing the sludge onto the soil surface and mixing with a surface layer of soil of $1 \mathrm{~m}$. A minimum amount of aeration was provided once a month and no water or nutrients were utilized. The intent was to limit external intervention thereby undertaking the bioremediation process with minimum cost. Encouraging results were obtained with $80 \%$ hydrocarbon biodegradation in 11 months.

\subsection{Composting}

Composting is a classical technology used in the treatment of agricultural and municipal solid wastes and sewage sludge, with the application of 
composting to soil bioremediation being somewhat more recent. The principle of operation consists of mixing the contaminated soil with nonhazardous organic amendments, generally other solid wastes (i.e., manure, agricultural wastes) suitable for composting applications, to encourage the development of bacterial populations able to degrade the pollutants in the soil via cometabolic pathways. The process is undertaken under aerobic conditions and takes advantage of the heat generated during the oxidative exothermic biodegradation reactions causing a significant temperature increase (about $50-60^{\circ} \mathrm{C}$ ). This temperature increase results in more efficient performance of the biological process. An additional positive characteristic of composting as a bioremediation technique is the production of mature compost that can be used in land restoration for industrial, municipal or housing developments depending on its final quality. ${ }^{65}$

Composting can be undertaken via a variety of approaches, with the simplest and cheapest being with the use of windrows that are long mounds in which the mixture of soil and amending agent are piled. Optimal size of the cross sectional area of the windrow is a key factor in determining the minimization of the heat losses. Regular mixing is required for aeration as well as for mixing of the soil; both of these operations can have unwanted consequences, namely, the emission of unpleasant odors and a loss of moisture. Typical sizes of cross sectional areas for windrows are 3-4 $\mathrm{m}$ wide and $1-1.5 \mathrm{~m}$ in height.

More advanced engineered solutions for composting are biopiles as well as vessel systems that are more expensive but provide a more effective control of the process with a consequent better efficiency and reduced volume of treated material. Biopiles are engineered cells constructed as aerated composted piles equipped with dissolved oxygen, moisture and nutrient control systems. Forced aeration is ensured by vacuum or injection systems. The treatment area is generally covered, and the bottom is provided with an impermeable liner to avoid leachate infiltration into soil and groundwater. Leachate is collected and sent to treatment or used in spray systems to control the moisture level in the pile.

Vessel compost systems are solid phase bioreactors fed with a soilamendment mixture in which all the relevant operating parameters (temperature, aeration, moisture and nutrient level) can be controlled at desired values. The negative features of these systems are the higher capital and operating costs, which limit their application to particularly critical treatment applications.

The success of composting in the bioremediation of contaminated soils depends on many physical, chemical and biological characteristics of the reaction environment. ${ }^{14} \mathrm{~A}$ key factor is the microbial accessibility to the pollutants, which is determined both by the operating conditions (mixing, moisture contents, soil composition), and by the characteristics of the amending agent that must be selected for each specific case. Sayara et al. ${ }^{14}$ 
investigated the effect of different organic amendments in the bioremediation of pyrene contaminated soil $(1 \mathrm{~g} / \mathrm{kg})$ by composting. They used the raw organic fraction of municipal solid wastes (OFMSW) as cosubstrates, as well as industrial and home compost from OFMSW, anaerobically digested sludge, activated sludge as received, and centrifuged activated sludge. The highest efficiency in terms of pyrene removal, 69\%, was obtained with the home compost derived from OFMSW while raw OFMSW did not show significant degradation.

Another key factor influencing composting performance is amendment stability, which was also extensively investigated by the same authors in the bioremediation of PAH-contaminated soil. ${ }^{66}$ They operated with different amending agents derived from the organic fractions of municipal wastes characterized by different stabilities (i.e., by different contents of easily biodegradable substrates). Stability was measured as maximum oxygen consumption rate through the Dynamic Respirometric Index (DRI): lower DRI max values indicate higher stability. It was found that compost stability had a marked effect on soil remediation, with the most stable compost being able to reach $92 \%$ and the least stable only 40\% PAH mixture degradation efficiency within the same reaction time. This can be explained by the higher availability, in the less stable composts, of easily biodegradable organic substrates, which are utilized as preferential substrates instead of PAHs. The authors also investigated the effect of contaminant concentration on the biodegradation kinetics and found, over the explored range of concentrations $(0.1-2 \mathrm{~g} / \mathrm{kg})$, that PAH concentration has a more significant effect in the lower range of tested concentrations in which the lowest degradation rates are observed. This finding is attributed to substrate limitation that is probably below the values required to observe appreciable biodegradation rates.

PAHs are the most investigated compounds in composting applications both at the laboratory and field scales, with a number of alternative composting amending agents being applied other than the ones already mentioned. Successful applications included the use of spent mushroom waste, ${ }^{67}$ soot waste, ${ }^{68}$ and maple leaves and alfalfa. ${ }^{69}$

Examples of the effective utilization of composting in biopiles are reported for oil bioremediation in cold climate regions. For example, Golodyaev et al. ${ }^{70}$ found biopiles to be a suitable method for bioremediation of oil contaminated soil (1.5\% of oil content in the compost pile) in the cold region of Northern Sakhalin (Russia). The main advantages of using biopiles in these regions include the marked temperature increase and the minimization of heat losses in the piles that promote good bioremediation performance. Moreover the authors found that the addition of fertilizers and lime favored the development of indigenous microcenoses, resulting in effective oil degradation with 95\% removal efficiency in 95 days. Sanscartier et al. ${ }^{71}$ investigated the effect of humidifying the air on the treatment of diesel contaminated soil $(11 \mathrm{~g} / \mathrm{kg})$ by an aerated/heated biopile system. Three 
field-scale biopiles were installed in the region of Kingston, Ontario, Canada and the experiments were performed for 10 months partly in the winter (average winter temperature $-6^{\circ} \mathrm{C}$ ). One biopile was aerated and heated; the second was aerated, heated, and also humidified; and the third was only aerated. The humidified system maintained an optimal moisture content over the entire experimental period and gave the best performance in terms of the residual hydrocarbon concentration in the soil. Moreover, the findings also suggested that humidification had a beneficial effect not only on biodegradation but also on decreasing volatilization.

The possibility of producing a compost suitable for reuse in land restoration has increased interest in using in-vessel composting, which provides better control of process performance. With this technological approach, higher temperatures can be utilized $\left(>70^{\circ} \mathrm{C}\right)$ for more efficient pathogen removal, and better control of the operating parameters (temperature, moisture content, mixing, amendment/soil ratio) promotes improvement of microbial activity and consequent contaminant degradation. ${ }^{65}$ In vessel composting bioremediation of aged coal tar soil was investigated by Antizar-Ladislao et al. ${ }^{72}$ to study the effect of the temperature and soil/amending agent ratio which were shown to be the most critical parameters for process performance. Green waste (consisting of a mixture of foodstuff, sawdust, leaves, grass, and wheat straw) was utilized as the amendment, with the ratio soil/green waste being in the range of 0.6-0.9, while three temperature values were tested $\left(38,55,70^{\circ} \mathrm{C}\right)$. The highest PAH removal efficiency, for a contamination level of $0.1 \mathrm{~g} / \mathrm{kg}$, was observed at $38^{\circ} \mathrm{C}$ and a soil amendment ratio of 0.8 . Interestingly, the lowest temperature value gave the best performance, and this finding can be explained by considering that higher temperatures could inhibit microbial diversity and hence the enzymatic potential of the system. This is in contrast to the present tendency of operating at higher temperatures (up to $70^{\circ} \mathrm{C}$ ) to attain the necessary degree of removal of pathogens required for compost utilization. If pathogen removal is required the authors suggest that the optimal strategy would be to operate with a temperature profile: an initial mesophilic stage (optimal conditions for PAHs removal) followed by a thermophilic stage (optimal condition for pathogen removal) and cooling and maturation stages. This requirement justifies the use of a more complex in-vessel system for composting. In the course of the experiments the organic matter dynamics were characterized by fluorescence excitation-emission spectroscopy, which was found to be an efficient tool to indicate the degree of humification (i.e., humic acid formation) or maturation of the compost. ${ }^{65}$

In addition to PAH bioremediation, composting has been applied to the treatment of soil contaminated with explosives ${ }^{8}$ and polychloro biphenils (PCBs), ${ }^{73}$ although to a lesser extent. Recent investigations also report the successful application of composting to the bioremediation of phenolic compounds. Khan and Anjaneyulu ${ }^{74}$ investigated the lab-scale composting of 
sediment and soil contaminated with a phenolic mixture $(0.016-0.024 \mathrm{~g} / \mathrm{kg})$ and benzene $(0.003-0.007 \mathrm{~g} / \mathrm{kg})$. They proposed a procedure consisting of the addition of a commercial fertilizer and commercial compost to the soil (or sediment), as nutrient and microorganism sources, respectively. Satisfactory results were obtained with the completion of the process in five weeks and with the production of a compost suitable for reuse as inoculum for the treatment of contaminated sites. Jiang et al. ${ }^{23}$ observed significant improvement in process performance in the remediation of pentachlorophenol contaminated soil $(0.1 \mathrm{~g} / \mathrm{kg})$ by composting with the addition of a white rot fungus the Phanarochaete chrysosporium. They utilized both free and immobilized $P$. chrysosporium, and obtained the best results with the immobilized fungus.

\subsection{Slurry Bioreactors}

Slurry bioreactors are currently the most highly engineered type of treatment system for soil bioremediation. The main advantage of this approach is accurate control of the bioremediation process, whose performance can be optimized by setting and controlling the most critical operating parameters. The main disadvantage is the high cost, which has to be justified for each particular application.

Slurry bioreactors are very powerful systems, but their successful implementation requires the availability of microbial cultures that are contaminantspecific, as well as effective solutions to optimize the process operating parameters (i.e., mixing and control systems). Slurry bioreactors have been employed as full-scale devices, and have been also extensively utilized for feasibility studies in a variety of bioremediation applications.

In classical slurry bioreactors contaminated soil is mixed with water or wastewater to give a slurry of predetermined consistency, with aqueous suspensions generally in the range of $10-30 \% \mathrm{w} / \mathrm{v}$, requiring an effective mixing device (mechanical or pneumatic). With such aqueous additions to slurry bioreactors the treatment and/or disposal of produced side streams therefore also has to be considered. The system can be operated under aerobic, anoxic and anaerobic conditions and in different feed modes: continuous, semicontinuous, and batch. Batch operation is the most commonly used mode offering better operability in the treatment of soils or sediments. As a modification of batch operation, the reactors are frequently operated as sequencing batch reactors (SBRs) with a work cycle consisting of feed phase (soil, water, and nutrient addition); reaction phase (the slurry is mixed and aerated [if necessary] until the desired decontamination degree is reached), settling, and extraction of the supernatant and of the decontaminated soil to be disposed of. Part of the slurry is left as inoculum for the next cycle.

Efficient performance of slurry bioreactors requires soil pretreatment consisting of crushing and screening of the coarser fractions $(0.85-4 \mathrm{~mm})$ that are directly disposed of while the fine fractions $(<0.85 \mathrm{~mm})$ are fed to 
the reactor for treatment. This strategy is applied in light of the fact that the pollutants are usually concentrated in the finest particles.

Slurry bioreactors were successfully and extensively applied for the removal of PAHs, with recent examples of application being reported in Venkata Mohan et al. ${ }^{12}$ and Prasanna et al. ${ }^{75}$ Venkata Mohan et al. ${ }^{12}$ investigated the effects of operating conditions on chrysene bioremediation by ex situ slurry phase bioreactors. The bioreactors were operated with a substrate load of 0.084 ( $\mathrm{g}$ chrysene $/ \mathrm{kg}$ soil $\mathrm{d}$ ) in single metabolic modes (aerobic, anaerobic, anoxic), mixed microenvironments (e.g., aerobic and anaerobic), with native microflora alone, and with added anaerobic sludge or domestic sewage. Data enveloping analysis (DEA) was employed to evaluate the process performance in terms of chrysene biodegradation. The results showed the best performance with anoxic metabolism in a mixed microenvironment with bioaugmentation of anaerobic sludge to the native microflora. It was also found that the optimization of the operating conditions could improve chrysene removal by $67 \%$. Prasanna et $a .^{75}$ studied the bioremediation of anthracene contaminated soil in a series of aerobic slurry bioreactors operated in sequencing batch mode (SBR) with different substrate loads ( 0.1 , $0.2,0.3 \mathrm{~g}$ anthracene $/ \mathrm{kg}$ soil $\mathrm{d}$ ) and with and without the addition of native flora with domestic sewage. The removal efficiency was found to decrease with substrate loading and a relevant beneficial effect was observed with bioaugmentation (89.6\% vs. 65.7\% removal efficiency with and without bioaugmentation, respectively).

At present aerobic processes are the most applied in the bioremediation of PAH contaminated soil but there is increasing experimental evidence of anaerobic PAH degradation in soil with nitrate and sulfate as terminal electron acceptors. ${ }^{76}$ This approach is a promising alternative in soil bioremediation especially in cases of reduced soil porosity and air permeability (i.e., oil spills) that make oxygen transfer in the system difficult. ${ }^{77}$ Lab-scale batch systems have been employed to investigate anaerobic PAH biodegradation for various soil types. Ambrosoli et al. ${ }^{78}$ achieved anaerobic biodegradation efficiencies in the range of 30-60\% under denitrifying conditions for different PAHs in the bioremediation of a contaminated soil $(0.14 \mathrm{~g} / \mathrm{kg})$ inoculated with a mixed bacterial population obtained from a paddy soil. Very high PAHs removal efficiencies ( $>80 \%$, after 90 days and temperature of $30^{\circ} \mathrm{C}$ ) have been also reported by Chang et al., ${ }^{79}$ using an anaerobic PAH-adapted consortium incubated with spiked soil $(0.002 \mathrm{~g} / \mathrm{kg})$ and amended with nutrients. They also found an improvement in degradation by supplying nutrients with the addition of acetate, lactate, or pyruvate. In a more recent study, Sayara et al. ${ }^{80}$ investigated the bioremediation of a PAH contaminated soil $(0.2-1 \mathrm{~g} / \mathrm{kg})$ under strict anaerobic-methanogenic conditions. They focused on the effect of PAH concentration and cosubstrate addition by utilizing different types of composts as amendments. They observed cumulative removal efficiencies in the range of $31-91 \%$ within a 50 -day incubation period for all 
the PAHs in the mixture, and a positive effect was provided by an increased PAH concentrations and the utilization of the mature compost.

A particular type of slurry system is the rotating drum bioreactor (RDB) 9 whose characteristic feature is the variety of internal devices that can be introduced with the goal of achieving better process control. RDBs allow easier optimization of the mixing conditions with consequent improvement of mass transfer efficiency and the beneficial effects of enhanced substrate and nutrient availability. Criteria for RDB design and operation were reported by Rodríguez Meza et al., ${ }^{9}$ who applied the system to a highly polluted soil $(55 \mathrm{~g} / \mathrm{kg})$ with petroleum hydrocarbons and investigated the effect of length/diameter ratio (L/D), rotational speed, and lifter type. The best results were obtained with the lowest L/D value (1.5), and with a helicoidal lifter (in comparison to the straight type) by increasing the rotating speed. In the optimized operating conditions the aerobic RDB, operated with natural convection, improved hydrocarbon removal by $30 \%$.

Slurry bioreactors have also been applied to the bioremediation of poorly degradable contaminants such as herbicides, pesticides and explosives. $^{28}$

Biodegradation of pendimethalin, a pre-emergence herbicide (used to destroy or prevent the growth of weeds) was carried out by Ramakhrisna et al. ${ }^{81}$ in a bioslurry reactor operated with native microflora augmented with sewage and they obtained 91\% removal efficiency. Bioremediation of the same compound was also investigated ${ }^{82}$ in a slurry phase bioreactor operated as an SBR (anoxic-aerobic-anoxic) at different soil-water ratios in the range of 1:5-1:25 and substrate loads in the range of 66-167 g/kg. Optimal performance was observed at a ratio of 1:20.

The effect of different operating conditions, electron acceptors, and additional carbon source were studied by Robles-Gonzalez et al. ${ }^{13}$ in the bioremediation of a mineral soil with a high clay and organic matter content contaminated with 2,4-dichlorophenoxyacetic acid $(0.3 \mathrm{~g} / \mathrm{kg})$, a widely used herbicide. They studied two parallel slurry bioreactors inoculated with aerobic, and with sulfate-reducing bacteria. The aerobic system gave better performance (93\%) in terms of overall removal efficiency while the sulfatereducing bacteria showed better specific removal rates. The addition of sucrose as a supplementary carbon source did not affect the performance of the aerobic biomass while a marked beneficial effect was observed for the sulfate-reducing bacteria.

Batch slurry bioreactors were utilized by Quintero et al. ${ }^{19}$ for the bioremediation of soils contaminated with lindane (y-hexachlorocyclohexane $[\mathrm{HCH}])$ one of the most widely used pesticides in agriculture in the last half century. They investigated the biodegradation in anaerobic fed batch bioreactors operating with granular sludge and added two co-substrates, volatile fatty acids or starch. The initial concentration of the $\mathrm{HCH}$ isomer mixture in the bioreactors was in the range of $0.1-0.4 \mathrm{~g} / \mathrm{kg}$. The influence of different 
reaction environmental conditions, initial concentration, cosubstrate addition, biomass concentration, and exchange factor (in terms of replaced soil/work volume) were also evaluated. The best results were obtained with starch at a biomass concentration of $8 \mathrm{gVSS} / 1$ and soil replacements of 10-20\%, with degradation efficiencies reaching $>90 \%$ for all lindane isomers. Efficient biodegradation of lindane isomers was also obtained by Quintero et al. ${ }^{22}$ in a slurry bioreactor operated with fungal biomass (white rot Bierkandera adusta). Degradation efficiencies were in the range of $30-95 \%$ depending on the degree of soil contamination $(0.025-0.1 \mathrm{~g} / \mathrm{kg}$ for each isomer) and on the type of $\mathrm{HCH}$ isomers.

Clark and Boopathy ${ }^{15}$ compared the performance of slurry bioreactors and landfarming for the bioremediation of nitroaromatics such as 2,4,6trinitrotoluene (TNT) at a contamination level of $10 \mathrm{~g} / \mathrm{kg}$ soil. The bioreactor operated with molasses as a co-substrate was more effective than landfarming, reaching 99\% TNT removal. High TNT percent removal (78-92\%) was also observed by Sheibani et al. ${ }^{16}$ in a slurry bioreactor treating a contaminated soil $(1 \mathrm{~g} / \mathrm{kg})$ supplemented with glucose as a cosubstrate and Tween 80 as surfactant.

Finally, an unconventional application of slurry bioreactors was proposed by Soda et al. ${ }^{83}$ for the treatment of arsenic contaminated soil using a dissimilatory arsenate-reducing bacterium. The principle of operation is based on bacterial reduction of As (V) to As(III), which can cause arsenic extraction from the solid phase, because As(III) is much less adsorptive than As $(\mathrm{V})$. In this case the catalytic action of the microorganism is not present in the biodegradation phase but in the previous extraction phase. The authors performed a preliminary study with Bacillus selenatarsenatis as the bioremediation agent and confirmed the effective action of the bacterial strain compared to the abiotic control experiment. Additional investigations are required to optimize the operating conditions.

\section{INNOVATIVE TECHNOLOGIES}

Before discussing innovative bioremediation strategies for the ex situ treatment of contaminated soil, it is necessary to first describe a physical treatment process developed in the 1990s: the Terra-Kleen Solvent Extraction Technology. ${ }^{84}$ This remediation technology is intended to remove organic compounds from soil, sludges, and sediments and in 1993 the Terra-Kleen technology was evaluated by the U.S. Environmental Protection Agency during a treatability study on soils from three different sites. The technology was also evaluated in the United States in 1994 during pilot-scale demonstration tests on soils contaminated with PCB in the commercial formulation of Aroclor 1260. 
The Terra-Kleen system is a batch process that operates at ambient temperatures and removes organic contaminants from soils by extracting them into flammable, proprietary solvents. After the soils are washed with solvent, the contaminated solvent passes through a recovery unit, in which contaminants are separated from the solvent and concentrated, reducing the volume of pollutant for disposal. The reclaimed solvent is recycled. Residual solvent in the soil is removed using vacuum extraction and biological treatment, which involves the addition of an active biological culture and nutrients to biodegrade residual solvent. After biological treatment, the soil is replaced on site. Terra-Kleen, therefore, is not a complete treatment process because it does not destroy the target contaminants in soil; rather, it is a process that concentrates the contaminants for more conventional off-site disposal (e.g., incineration, landfilling).

Treated soils can be replaced on site once the solvent residuals have been reduced, however, solvent extraction will also remove natural organic and some inorganic biological nutrients such as nitrates and phosphates, requiring that a nutrient supplement containing natural nutrients be added to the soil after it is replaced on site. Limitations of the Terra-Kleen process include the requirement to purchase and use large volumes of flammable solvents, the fact that final treatment is not achieved by the process, and that contaminated soils with greater than $15 \%$ clays or fines, or more than $20 \%$ moisture are difficult to treat. In the former case this is because contaminants are strongly sorbed to the soil particles, and in the latter case the soil must be dried prior to treatment as excess water dilutes the solvent.

\subsection{Liquid-Liquid TPPBs}

At the time that the Terra-Kleen process was being developed, the first articles on TPPBs were being published. TPPBs consist of a cell-containing aqueous phase and an immiscible organic phase (initially an organic solvent) that can sequester large amounts of toxic substrates, while maintaining sub-inhibitory levels of substrates in the aqueous phase. The difference in substrate concentration between the two phases arises from the selective partitioning of organic substrates into the organic phase based on the partition coefficient of solute within this ternary system. As the microorganisms consume substrate from the aqueous phase, additional substrate partitions into the aqueous phase to maintain the thermodynamic equilibrium of the system. In this way, very large amounts of toxic substrates can be added to a biotreatment system without causing cytotoxicity to the cells, and process operation is determined by cell metabolism and thermodynamic phase equilibrium.

Substrate loading of TPPBs requires that the solute be dissolved in the solvent phase, which can easily be envisaged for situations in which contaminants are stored as relatively pure materials, awaiting treatment or disposal. 
In the case of treating contaminated soil, however, direct contact of the solvent with the soil would be required, in a manner similar to that used by the Terra-Kleen process. In the case of TPPBs, however, the contaminant-laden solvent would not merely be distilled to concentrate the contaminant, but would be added to a bioreactor, and the pollutant degraded biologically. Additionally, the solvents generally used in TPPBs have been nonvolatile, resulting in few losses and allowing ready reuse. Collins and Daugulis ${ }^{85}$ provided a demonstration of concept for the removal (>99\%) of a mixture of benzene, toluene, and xylene from sand using a high-boiling organic solvent, with subsequent transfer of the solvent for BTX biodegradation in a TPPB. The solvent was used a second time with equivalent effectiveness. Although successful in demonstrating the key elements of removing a contaminant by contacting with an organic solvent, and subsequent biological degradation (not just concentration for conventional disposal), this study used sand as a proxy for soil, which is obviously an easier matrix to treat.

\subsection{Solid-Liquid TPPBs}

In both the Terra-Kleen concentration process and the TPPB biotreatment technology, direct contact of soil with relatively large amounts of organic solvents is required. Clearly this raises some practical concerns, including solvent losses, residual solvent in the soil, solvent handling and of course cost. To address these issues, Amsden et al. ${ }^{86}$ showed that the immiscible organic phase of TPPBs can be replaced with inexpensive commercial polymers that function in exactly the same way (solute absorption via equilibrium considerations) as do organic solvents.

Prpich et al. ${ }^{87}$ demonstrated the complete technological cycle of the biotreatment of phenol in soil, shown schematically in Figure 1, by (a) contacting the soil with polymer beads to remove the contaminant, (b) transferring the polymer beads to a TPPB bioreactor to allow a mixed consortium to degrade the absorbed pollutant, and (c) reusing the beads twice in the same manner with equivalent efficacy.

The polymer in this instance was the DuPont thermoplastic Hytrel 8206, which was able to sorb greater than $95 \%$ of the contaminant (initial concentration $2.3 \mathrm{~g} / \mathrm{kg}$ ) from the soil in approximately $24 \mathrm{hr}$, and release it completely for degradation in the TPPB. This cycle was repeated twice more, with the same polymer beads, with no decrease in treatment efficiency.

The TPPB strategy of using polymers to sorb contaminants from terrestrial matrices has also been demonstrated for the remediation of PAHs (a mixture of phenanthrene, pyrene, and fluoranthene) contaminated soil with excellent results. ${ }^{88}$ All experiments were conducted with contaminated $(0.9 \mathrm{~g} / \mathrm{kg})$ artificial soil consisting of 10\% organics (peat), 20\% clay, and $70 \%$ industrial sand at pH 6 as described in the Organization for Economic Cooperation and Development method 207. ${ }^{89}$ The polymer to soil ratio was 


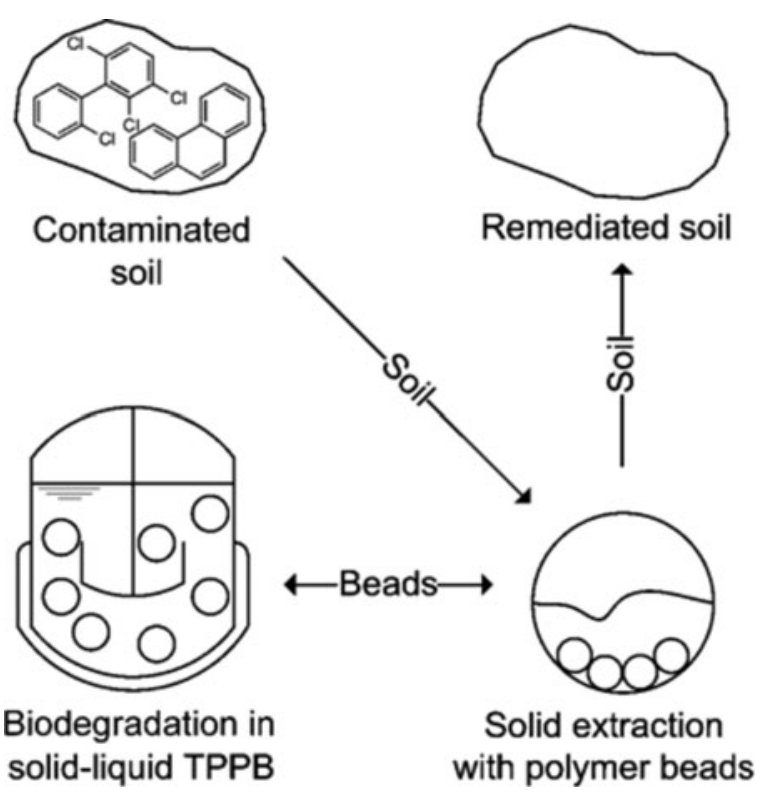

FIGURE 1. Schematic diagram of the polymer-TPPB treatment strategy for remediating organic pollutants in soil.

$10 \%(\mathrm{w} / \mathrm{w})$ and although the amounts of PAHs remaining in soil and sorbed by the polymer after $48 \mathrm{hr}$ were equal, the final concentration in the polymer (Desmopan) was 10 times higher than in the soil, showing the high affinity of the polymer for the target PAHs. After uptake of PAHs from the soil, the polymers were transferred to a TPPB in which a microbial consortium degraded approximately 78\%, 62\%, and 36\% of phenanthrene, pyrene, and fluoranthene, respectively, within a 14-day period. Figure 2 shows the marked uptake of fluoranthene by polymer beads.

PCBs (Aroclor 1242) were also removed from the same soil as above using $1 \%$ and $10 \%(\mathrm{w} / \mathrm{w})$ polymer-to-soil ratios. ${ }^{90}$ Initial PCB contamination levels of 0.1 and $1 \mathrm{~g} / \mathrm{kg}$ could be reduced to $32 \%$ and to $41 \%$ of the original value after 48-hr mixing, in this case with the assistance of a mobilizing agent. The Aroclor-laden polymer beads (Hytrel) were then added to a TPPB in which the PCB degrading organism Burkholderia xenovorans LB400 degraded a total of $70 \mathrm{mg}$ Aroclor in a 11 solid-liquid TPPB within $80 \mathrm{hr}$ of operation.

Recently it has also been shown that thermoplastic polymers can be mixed with magnetic beads to facilitate the removal of the contaminant-laden polymers from soil and/or water after uptake. ${ }^{91}$ This work also showed that the absorptive capacity of the magnetic polymer beads was only minimally affected by the presence of the magnetic particles, and also that a simple 


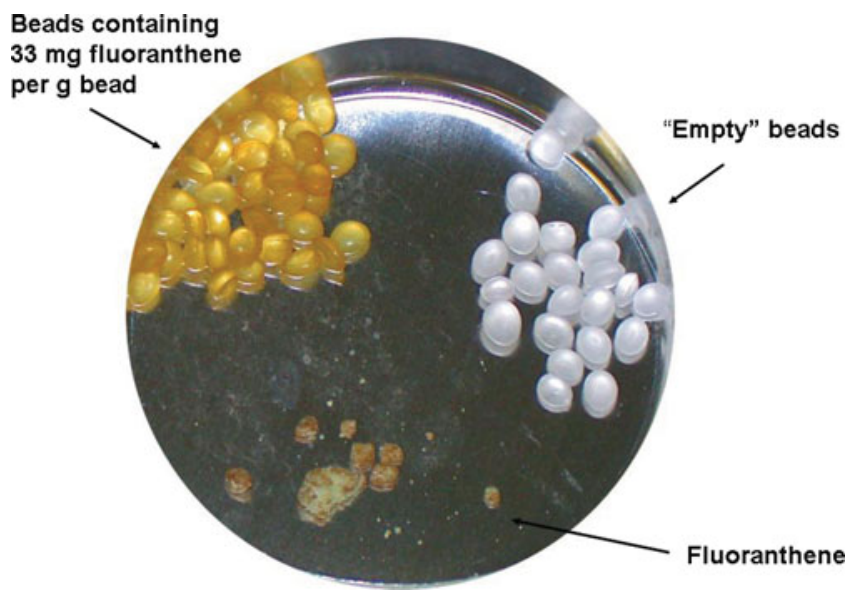

FIGURE 2. Uptake of fluoranthene by polymer beads. Polymer: Desmopan 9370 A (Bayer Canada, Toronto, Ontario, Canada). (Color figure available online).

means to enhance removal from the contaminated materials can be employed. These magnetic beads, after removing the contaminant from soil, were also added to a TPPB, for rapid and complete mineralization of the target pollutant (phenol).

The use of polymers for the remediation of soil, and their addition to a TPPB for final contaminant degradation, has a number of advantages over the use of organic solvents for the removal of contaminants from soil. These include the completely inert nature of (most) polymers making them completely biocompatible with the terrestrial environments in which they are used, as well as with the microorganisms in TPPBs; their nonbioavailability to degrading organisms; their ease of complete removal from the treated soil with no solvent residual to deal with; their nonvolatility, nonflammability, ease of handling, and safety; their tailoring to almost any contaminant; and their extremely low cost.

\section{DISCUSSION AND RESEARCH NEEDS}

Table 2 provides an overview of the available technologies and their level of application. It can be seen that there are significant differences in the technological levels of the various methods, from the simple excavation and placement of contaminated soils in landfarming, to controlled systems such as bioreactors whose complexity is similar to that of industrial reactors. The established classical technologies of landfarming and composting have been extensively utilized in the past, but their application has generally been limited to PAHs and other hydrocarbons. Their use arose from the extensive development of the petrochemical industry, which contributed to 
TABLE 2. Overview of the ex situ available technologies in soil bioremediation and level of application

\begin{tabular}{|c|c|c|c|}
\hline Technology & $\begin{array}{l}\text { Principle of } \\
\text { operation }\end{array}$ & $\begin{array}{l}\text { Level of } \\
\text { application }\end{array}$ & References \\
\hline Landfarming & $\begin{array}{l}\text { Excavation and placement of } \\
\text { contaminated soils into lined } \\
\text { beds. Aeration is provided by } \\
\text { periodic tilling. }\end{array}$ & Full scale & $8,59,77$ \\
\hline Composting & $\begin{array}{l}\text { Mixing the contaminated soil } \\
\text { with nonhazardous organic } \\
\text { amendments, generally other } \\
\text { solid wastes suitable for } \\
\text { composting applications. }\end{array}$ & Full scale & $2,8,77$ \\
\hline Bioreactors & $\begin{array}{l}\text { Selected culture in a controlled } \\
\text { reaction environment. }\end{array}$ & & \\
\hline Slurry & $\begin{array}{l}\text { Contaminated soil is treated in } \\
\text { aqueous suspension (10 to } 30 \% \\
\text { w/v) in bioreactors equipped } \\
\text { with an effective mixing device } \\
\text { (mechanical or pneumatic). }\end{array}$ & Full scale & $28,59,92$ \\
\hline \multicolumn{4}{|c|}{ 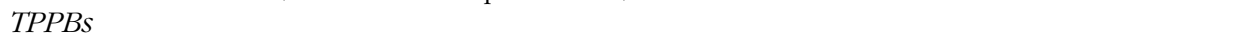 } \\
\hline Liquid-liquid & $\begin{array}{l}\text { Extraction of contaminant into } \\
\text { organic solvent, and delivery } \\
\text { of substrate to microbes in a } \\
\text { bioreactor. }\end{array}$ & $\begin{array}{l}\text { Pilot-scale } \\
\text { demonstration }\end{array}$ & 93 \\
\hline Solid-liquid & $\begin{array}{l}\text { Extraction of contaminants by } \\
\text { polymer beads and delivery of } \\
\text { substrate to microbes in a } \\
\text { bioreactor. }\end{array}$ & $\begin{array}{l}\text { Lab-scale } \\
\text { demonstration }\end{array}$ & 88 \\
\hline
\end{tabular}

the most significant soil pollution cases in the twentieth century. In more recent decades other toxic xenobiotic compounds have been synthesized and discharged, or improperly disposed of, into soil, which has often been the final destination of industrial wastes. Soil pollution has become a more severe environmental concern due to both the increased pollution load and the newly discharged xenobiotic pollutants, which have often been foreign to the indigenous microflora. Because of these emerging challenges for soil bioremediation low-tech methods are often not appropriate, and some improvements are required. A promising approach to enhance the performance of ex situ technologies is the integration of the basic technologies with specific strategies summarized in Table 3 . There are two different routes that the can be followed: (a) biological methods capable of increasing the performance of the biodegradation process with more efficient bacterial strains (bioaugmentation) or by addition of more amenable substrates or nutrients (biostimulation); and (b) chemical physical methods acting in varying modes to facilitate the biological reaction in terms of substrate availability, including solvent extraction, surfactant addition, and thermal and oxidative pretreatments. 
TABLE 3. Overview of the strategies to enhance the performance of ex situ soil bioremediation technologies and level of application

\begin{tabular}{|c|c|c|}
\hline Strategy & Principle of operation & Level of application \\
\hline Bioaugmentation & $\begin{array}{l}\text { Inoculation of } \\
\text { enriched/acclimated } \\
\text { consortia or strains to the } \\
\text { native microflora }\end{array}$ & $\begin{array}{l}\text { - Full-scale application } \\
\text { - Under investigation for the } \\
\text { selection of new more } \\
\text { effective and } \\
\text { contaminant-specific strains }\end{array}$ \\
\hline Biostimulation & $\begin{array}{l}\text { Addition of appropriate } \\
\text { nutrients and/or readily } \\
\text { biodegradable substrates }\end{array}$ & $\begin{array}{l}\text { - Full-scale application for } \\
\text { nutrients } \\
\text { - Under investigation for low } \\
\text { cost substrates (i.e., waste } \\
\text { materials) }\end{array}$ \\
\hline Solvent extraction & $\begin{array}{l}\text { Solvent extraction of the } \\
\text { contaminant from the solid } \\
\text { to the liquid phase and } \\
\text { subsequent solvent } \\
\text { bioregeneration }\end{array}$ & $\begin{array}{l}\text { - Full-scale application for soil } \\
\text { washing } \\
\text { - Under investigation for } \\
\text { TPPBs }\end{array}$ \\
\hline Surfactant addition & $\begin{array}{l}\text { Surfactants are mobilizing } \\
\text { agents for hydrophobic } \\
\text { pollutants in that facilitate } \\
\text { their desorption from the } \\
\text { soil matrix }\end{array}$ & $\begin{array}{l}\text { - Full-scale application for } \\
\text { "classical surfactants" (i.e., } \\
\text { Tween 80) } \\
\text { - Under investigation for } \\
\text { nontoxic biodegradable } \\
\text { extracting agents }\end{array}$ \\
\hline Thermal pretreatment & $\begin{array}{l}\text { Increase of the diffusion rate } \\
\text { (and consequently of mass } \\
\text { transfer rate and } \\
\text { bioavailability) }\end{array}$ & - Full-scale application \\
\hline $\begin{array}{l}\text { Oxidative } \\
\text { pretreatment }\end{array}$ & $\begin{array}{l}\text { Partial oxidation of the } \\
\text { contaminant to increase } \\
\text { bioavailability and } \\
\text { biodegradability }\end{array}$ & $\begin{array}{l}\text { - Full-scale application for } \\
\text { Ozone } \\
\text { - Under investigation for other } \\
\text { more effective oxidizing } \\
\text { agents }\end{array}$ \\
\hline
\end{tabular}

Note. The level of application was determined by assessing numerous literature reports from a variety of sources.

Biological methods are in principle more environmentally sustainable in that no other reagents (to be removed or disposed of) are added to the system, and in the case of biostimulation the added substrates can be waste materials so a double objective of degrading the soil pollutants as well as the added waste substrates is achieved. Conversely, stable performance is not always easily attainable in biological systems with low rates characterizing such biological processes.

Chemical/physical methods require the addition of reagents (solvents, surfactants, oxidative agents) or energy input (in thermal pretreatment) and are less sustainable, but can ensure more stable performance and higher reaction rates. A promising alternative to organic solvents and surfactants, still under investigation, is the addition of biodegradable extracting agents 
(i.e., BioSolve and vegetable oils as solvents and cyclodextrins and rhamnolipids as surfactants) that, in contrast to chemical reagents, do not require subsequent treatment and/or disposal but can be biodegraded by the same organisms operating in the bioremediation process.

Another innovative technology (described in detail in this review) to maximize the efficiency of a soil bioremediation process with no parallel production of streams to be treated or disposed is the TPPB concept, as an alternative to the single-phase slurry bioreactors. TPPBs provide an integration of a chemical/physical step (solvent or polymer use to remove the pollutant from soil) with a biological process. In this case, the partitioning phase can be considered to be a temporary storage phase for the contaminant, which is subsequently removed in the subsequent biological step thereby allowing the reuse of the partitioning phase. The system has been tested with solvents and can be considered to be an evolution of soil washing in which the solvent can be reused for a number of work cycles. The recent proposed utilization of polymers as an alternative to solvents for contaminant removal from soil is potentially more advantageous due to the absolute biocompatibility and inert behavior of the polymer beads with respect to the soil being treated, and the biomass operating within the TPPB system. In addition the extremely low polymer cost in a relevant added value of this technology. With the aim of reducing the cost and improving sustainability, a new opportunity for this technology has recently been identified, via the use of recycled polymeric materials as the sequestering phase. A first application has demonstrated the feasibility of this strategy for the uptake and bioremediation of hydrocarbons employing used automobile tires. ${ }^{94}$

In conclusion, an analysis of the available ex situ technologies has confirmed the significant potential of this approach in soil bioremediation especially for severely contaminated sites requiring safe and rapid solutions. Table 4 shows a summary statement of the main groups of compounds and the related applied ex situ technologies for their bioremediation.

Research needs in the field require both the improvement of the performance of existing available technologies, that in some case are not sufficiently engineered for efficient process performance, as well as the development of engineered solutions characterized by reduced costs appropriate for application. To this end solid-liquid TPPBs are a promising alternative: the remediation of a number of contaminants by uptake into polymer beads and mineralization in TPPBs has been demonstrated to be rapid, effective and potentially very cost effective. Because of the very large number of inexpensive commercial thermoplastics available, it is possible to rationally select and match absorptive polymers for particular contaminant(s), in contrast to the limited number of organic solvents that can be used to extract and deliver particular contaminants in TPPBs. The next logical step in developing and implementing this technology is larger scale field applications to 
TABLE 4. Summary of the groups of compounds and related technologies applied for their ex situ bioremediation

\begin{tabular}{llc}
\hline Compound & Applied technology & References \\
\hline PAHs & Landfarming & 59 \\
& Composting & 77 \\
& Slurry bioreactors & 28 \\
Hydrocarbons & TPPBs & 88 \\
& Landfarming & 59 \\
& Composting & 28 \\
PCBs & Slurry bioreactors & 28 \\
& TPPBs & 87 \\
Phenolic compounds & Slurry bioreactors & 28 \\
& TPPBs & 90 \\
\multirow{2}{*}{ Explosives } & Landfarming & 59 \\
& Composting & 28 \\
Pesticides & TPPBs & 94 \\
& Composting & 59 \\
& Slurry bioreactors & 28 \\
& TPPBs & 95 \\
& Landfarming & 2 \\
& Slurry bioreactors & 28,59 \\
\hline
\end{tabular}

demonstrate both technical and cost effectiveness relative to more conventional soil remediation technologies.

\section{REFERENCES}

[1] Kirchhoff, M. M. (2003). Promoting green engineering through green chemistry. Environ. Sci. Technol., 37, 5349.

[2] Juwarkar, A. A., Singh, S. K., and Mudhoo, A. (2010). A comprehensive overview of elements in bioremediation. Rev. Environ. Sci. Biotechnol., 9, 215.

[3] Cerniglia, C. E. (2003). Recent advances in the biodegradation of polycyclic aromatic hydrocarbons by Micobacterium species. In V. Sasek, J. A. Glaser, and P. Baveye (Eds.), The utilization of bioremediation to reduce soil contamination: Problems and solutions (pp. 51 -73). Dordrecht, the Netherlands: Kluwer Academic

[4] Bento, F. M., Camargo, F. A. O., Okeke, B. C., and Frankenberger, W. T. (2005). Comparative bioremediation of soils contaminated with diesel oil by natural attenuation, biostimulation and bioaugmentation. Bioresource Technol., 96, 1049.

[5] Bhalerao, T. S., and Puranik, P. R. (2007). Biodegradation of organochlorine pesticide, endosulfan by a fungal soil isolate, Aspergillus niger. Int. Biodeter. Biodegr., 59, 315.

[6] Vidali, M. (2001). Bioremediation. An overview. Pure App. Chem., 73, 1163.

[7] Krishna, K. R., and Philip, L. (2011). Bioremediation of single and mixture of pesticide-contaminated soils by mixed pesticide-enriched cultures. Appl. Biochem. Biotechnol., 164, 1257. 
[8] Castelo-Grande, T., Augusto, P. A., Monteiro, P., Estevezc, A. M., and Barbosa, D. (2010). Remediation of soils contaminated with pesticides: a review. Intern. J. Environ. Anal. Chem., 90, 438.

[9] Rodríguez-Meza, M. A., Chávez-Gomez, B., Poggi-Varaldo, H. M., Ríos-Leal, E., and Barrera-Cortes, J. (2010). Design of a new rotating drum bioreactor operated at atmospheric pressure on the bioremediation of a polluted soil. Bioprocess Biosyst. Eng., 33, 573.

[10] Biswas, S. S. K., Chaudhari, S., and Mukherji, S. (2005). Microbial uptake of diesel oil sorbed on soil and oil spill clean-up sorbents. J. Chem. Technol. Biotechnol., 80, 587.

[11] Lei, L., Khodadoust, A. P., Suidan, M. T., and Tabak, H. H. (2005). Biodegradation of sediment-bound PAHs in field contaminated Sediment. Water Res., 39, 349.

[12] Venkata Mohan, S., Purushotham Reddy, B., and Sarma, P. M. (2009). Ex situ slurry phase bioremediation of chrysene contaminated soil with the function of metabolic function: Process evaluation by data enveloping analysis (DEA) and Taguchi design of experimental methodology (DOE). Bioresource Technol., 100, 164.

[13] Robles-González, I., Ríos-Leal, E., Ferrera-Cerrato, R., Esparza-García, F., Rinderkenecht-Seijas, N., and Poggi-Varaldo, H. M. (2006). Bioremediation of a mineral soil with high contents of clay and organic matter contaminated with herbicide 2,4-dichlorophenoxyacetic acid using slurry bioreactors: effect of electron acceptor and supplementation with an organic carbon source. Process Biochem., 41, 1951.

[14] Sayara, T., Sarrà, M., and Sánchez, A. (2009). Preliminary screening of cosubstrates for bioremediation of pyrene-contaminated soil through composting. J. Hazard. Mater., 172, 1695.

[15] Clark, B., and Boopathy, R. (2007). Evaluation of bioremediation methods for the treatment of soil contaminated with explosives in Louisiana Army Ammunition Plant, Minden, Louisiana. J. Hazard. Mater., 143, 643.

[16] Sheibani, G., Naeimpoor, F., and Hejazi, P. (2011). Statistical factor-screening optimization in slurry phase bioremediation of 2,4,6-trinitrotoluene contaminated soil. J. Hazard. Mater., 188, 1.

[17] Vasilyeva, G. K., and Strijakova, E. R. (2007). Bioremediation of soils and sediments contaminated by polychlorinated biphenyls. Microbiology., 76, 639.

[18] Pavlostathis, S. G., Prytula, M. T., and Yeh, D. H. (2003). Potential and limitations of microbial reductive dechlorination for bioremediation applications. Water Air Soil Poll., 3, 117.

[19] Quintero, J. C., Moreira, M. T., Lema, J. M., and Feijoo, G. (2006). An anaerobic bioreactor allows the efficient degradation of $\mathrm{HCH}$ isomers in soil slurry. Chemosphere, 63, 1005.

[20] Garon, D., Sage, L., and Seigle-Murandi, F. (2004). Effects of fungal bioaugmentation and cyclodextrin amendment on fluorene degradation in soil slurry. Biodegradation, 15, 1.

[21] Garon, D., Sage, L., Wouessidjewe, D., and Seigle-Murandi, F. (2004). Enhanced degradation of fluorine in soil slurry by Absidia cylindrospora and maltosylcyclodextrin. Chemosphere, 56, 159. 
[22] Quintero, J. C., Lú-Chau, T. A., Moreira, M. T., Feijoo, G., and Lema, J. M. (2007). Bioremediation of $\mathrm{HCH}$ present in soil by the white-rot fungus Bjerkandera adusta in a slurry batch bioreactor. Int. Bioter. Biodeg., 60, 319.

[23] Jiang, X., Zeng, G., Huang, D., Chen, Y., Liu, F., Huang, G., Li, J., Xi, B., and Liu, H. (2006). Remediation of pentachlorophenol-contaminated soil by composting with immobilized Phanerochaete chrysosporium, World J. Microbiol. Biotechnol., 22, 909.

[24] Abd El Rahim, W. M., Moawad, H., and Khalafallah, M. (2003). Microflora involved in textile dye waste removal. J. Basic Microbiol., 43, 167.

[25] Gogoi, B. K., Dutta, N. N., Goswami, P., and Krishna Mohan, T. R. (2003). A case study of bioremediation of petroleum-hydrocarbon contaminated soil at a crude oil spill site. Adv. in Environ. Res., 7, 767.

[26] Kristensen, A. H., Poulsena, T. G., Mortensen, L., and Moldrup, P. (2010). Variability of soil potential for biodegradation of petroleum hydrocarbons in a heterogeneous subsurface. J. Hazard. Mater., 179, 573.

[27] Caravaca, F., and Roldan, A. (2003). Assessing changes in physical and biological properties in a soil contaminated by oil sludges under semiarid Mediterranean conditions. Geoderma, 117, 53.

[28] Robles-González, I., Fava, F., and Poggi-Varaldo, H. M. (2008). A review on slurry bioreactors for bioremediation of soils and sediments. Microbial Cell Factories, 7, 5.

[29] Di Toro, S., Zanaroli, G., and Fava, F. (2006). Intensification of the aerobic bioremediation of an actual site soil historically contaminated by polychlorinated biphenyls (PCBs) through bioaugmentation with a nonacclimated, complex source of microorganisms. Microb. Cell Fact., 5, 11.

[30] Zheng, Z. M., and Obbard, J. P. (2003). Oxidation of polycyclic aromatic hydrocarbons by fungal isolates from oil contaminated refinery soil. Environ. Sci. Pollut. Res., 10, 173.

[31] Hamdi, H., Benzarti, S., Manusadzianas, L., Aoyama, I., and Jedidi, N. (2007). Bioaugmentation and biostimulation effects on PAH dissipation and soil ecotoxicity under controlled conditions. Soil Biol. Biochem., 39, 1926.

[32] Rocchetti, L., Beolchini, F., Ciani, M., and Dell'Anno, A. (2011). Improvement of bioremediation performance for the degradation of petroleum hydrocarbons in contaminated sediments. Appl. Environ. Soil Sci. doi:10.1155/2011/319657.

[33] El Fantroussi, S., and Agathos, S. N. (2005). Is bioaugmentation a feasible strategy for pollutant removal and site remediation? Curr. Opin. Microbiol., 8, 268.

[34] Gentry, T. J., Rensing, C., and Pepper, I. L. (2004). New approaches for bioaugmentation as a remediation technology. Crit. Rev. Environ. Sci. Technol., 34, 447.

[35] Tang, Y., Qi, J. L., and Krieger-Brockett, B. (2005). Evaluating factors that influence microbial phenanthrene biodegradation rates by regression with categorical variables. Chemosphere, 59, 729.

[36] Betancur-Galvis, L. A., Alvarez-Bernal, D., Ramos-Valdivia, A. C., and Dendooven, L. (2006). Bioremediation of polycyclic aromatic hydrocarboncontaminated saline-alkaline soils of the former Lake Texcoco. Chemosphere, 62,1749 . 
[37] Taylor, L. T., and Jones, D. M. (2001). Bioremediation of coal tar PAH in soils using biodiesel. Chemosphere, 44, 1131.

[38] Chang, B. V., Shiung, L. C., and Yuan, S. Y. (2002). Anaerobic biodegradation of polycyclic aromatic hydrocarbon in soil. Chemosphere, 48, 717.

[39] Gong, Z., Alef, K., Wilke, B., Mai, M., and Li, P. (2005). Assessment of microbial respiratory activity of a manufactured gas plant soil after remediation using sunflower oil. J. Hazard. Mater., 124, 217.

[40] Xu, R., Lau, N. L., Lim, Y. G., and Obbard, J. P. (2005). Bioremediation of oilcontaminated sediments on an inter-tidal shoreline using a slow-release fertilizer and chitosan. Mar. Pollut. Bull., 51, 1062.

[41] Tyagi, M., da Fonseca, M. M. R., and de Carvalho, C. C. C. R. (2011). Bioaugmentation and biostimulation strategies to improve the effectiveness of bioremediation processes. Biodegradation, 22, 231.

[42] Namkoong, W., Hwang, E. Y., Park, J. S., and Choi, J. Y. (2002). Bioremediation of diesel-contaminated soil with composting. Environ. Pollut., 119, 23.

[43] Haritash, A. K., and Kaushik, C. P. (2009). Biodegradation aspects of Polycyclic Aromatic Hydrocarbons (PAHs): A review. J. Hazard. Mater., 169, 1.

[44] Khodadoust, A. P., Bagchi, R., Suidan, M. T., Brenner, R. C., and Sellers, N. G. (2000). Removal of PAHs from highly contaminated soils found at prior manufactured gas operations. J. Hazard. Mater., B80, 159.

[45] Christofi, N., and Ivshina, I. B. (2002). Microbial surfactants and their use in field studies of soil remediation: A review. J. Appl. Microbiol., 93, 915.

[46] Kosaric, N. (2001). Biosurfactants and their application for soil bioremediation. Food Technol. Biotechnol., 39, 295.

[47] Das, N., and Chandran, P. (2011). Microbial degradation of petroleum hydrocarbon contaminants: An overview. Biotechnol. Res. Int. doi:10.4061/2011/941810.

[48] Jennings, E. M., and Tanner, R. S. (2000, May). Biosurfactant-producing bacteria found in contaminated and uncontaminated soils. Proceedings of the 2000 Conference on Hazardous Waste Research, Denver, Colorado.

[49] Montoneri, E., Boffa, V., Savarino, P., Tambone, F., Adani, F., Micheletti, L., Gianotti, C., and Chiono, R. (2009). Use of biosurfactants from urban wastes compost in textile dyeing and soil remediation. Waste Manage., 29, 383.

[50] Bordas, F., Lafrance, P., and Villemur, R. (2005). Conditions for effective removal of pyrene from an artificially contaminated soil using Pseudomonas aeruginosa 57SJ rhamnolipids. Environ. Pollut., 138, 69.

[51] Johnsen, A. R., Wickb, L. Y., and Harms, H. (2005). Principles of microbial PAH-degradation in soil. Environ. Pollut., 133, 71.

[52] Zhao, B., Zhu, L., Li,W., and Chen, B. (2005). Solubilization and biodegradation of phenanthrene in mixed anionic-nonionic surfactant solutions. Chemosphere, $58,33$.

[53] Viglianti, C., Hanna, K., De Brauer, C., and Germain, P. (2006). Removal of polycyclic aromatic hydrocarbons from aged-contaminated soil using cyclodextrins: Experimental study. Environ. Pollut., 140, 427.

[54] Berselli, S., Milone, G., Canepa, P., Di Gioia, D., and Fava, F. (2004). Effects of cyclodextrins, humic substances, and rhamnolipids on the washing of a historically contaminated soil and on the aerobic bioremediation of the resulting effluents. Biotechnol. Bioeng., 88, 1. 
[55] Haapea, P., and Tuhkanen, T. (2006). Integrated treatment of PAH contaminated soil by soil washing, ozonation and biological treatment. J. Hazard. Mater., B136, 244.

[56] Liang, Y., Van Nostrand, J. D., Wang, J., Zhang, X., Zhou, J., and Li, G. (2009). Microarray-based functional gene analysis of soil microbial communities during ozonation and biodegradation of crude oil. Chemosphere, 75, 193.

[57] Kulik, N., Goi, A., Trapido, M., and Tuhkanen, T. (2006). Degradation of polycyclic aromatic hydrocarbons by combined chemical pre-oxidation and bioremediation in creosote contaminated soil. J. Environ. Manage., 78, 382.

[58] Piskonen, R., and Itävaara, M. (2004). Evaluation of chemical pretreatment of contaminated soil for improved PAH bioremediation. Appl. Microbiol. Biotechnol., 65, 627.

[59] Kalogerakis, N. (2011). Ex situ bioremediation of contaminated Soils: from biopiles to slurry phase bioreactors. In A. I. Koukkou (Ed.), Microbial bioremediation of non-metals: Current research. Portland, OR: Caster.

[60] Rubinos, D. A., Villasuso, R., Muniategui, S., Barral, M. T., and Díaz-Fierros, F. (2007). Using the landfarming technique to remediate soils contaminated with hexachlorocyclohexane isomers. Water Air Soil Pollut., 181, 385.

[61] Gallego, J. R., Sierra, C., Villa, R., Peláez, A. I., and Sánchez, J. (2010). Weathering processes only partially limit the potential for bioremediation of hydrocarbon-contaminated soils. Org. Geochem., 41, 896.

[62] McCarthy, K., Walker, L., Vigoren, L., and Bartel, J. (2004). Remediation of spilled petroleum hydrocarbons by in situ landfarming at an arctic site. Cold Reg. Sci. Technol., 40, 31.

[63] Paudyn, K., Rutter, A., Kerry Rowe, R., and Poland, J. S. (2008). Remediation of hydrocarbon contaminated soils in the Canadian Arctic by landfarming. Cold Reg. Sci. Technol., 53, 102.

[64] Marin, J. A., Hernandez, T., and Garcia, C. (2005). Bioremediation of oil refinery sludge by landfarming in semiarid conditions: Influence on soil microbial activity. Environ. Res., 98, 185.

[65] Antizar-Ladislao, B., Lopez-Real, J., and Beck, A. J. (2006). Investigation of organic matter dynamics during in-vessel composting of an aged coal-tar contaminated soil using fluorescence excitation-emission spectroscopy. Chemosphere, 64, 839.

[66] Sayara, T., Sarrà, M., and Sánchez, A. (2010). Effect of compost stability and contaminant concentration on the bioremediation of PAHs contaminated soil through composting. J. Hazard. Mater., 179, 999.

[67] Lau, K. L., Tsang, Y. Y., and Chiu, S. W. (2003). Use of spent mushroom compost to bioremediate PAH-contaminated samples. Chemosphere, 52, 1539.

[68] Moretto, L. M., Silvestri, S., Ugo, P., Zorzi, G., Abbondanzi, F., Baiocchi, C., and Iacondini, B. (2005). Polycyclic aromatic hydrocarbons degradation by composting in a soot-contaminated alkaline soil. J. Hazard. Mater., 126, 141.

[69] Haderlein, A., Legros, R., and Ramsay, B. A. (2006). Pyrene mineralization capacity increases with compost maturity. Biodegradation, 17, 293.

[70] Golodyaev, G. P., Kostenkov, N. M., and Oznobikhin, V. I. (2009). Bioremediation of oil-contaminated soils by composting. Eurasian Soil Sci., 42, 926. 
[71] Sanscartier, D., Zeeb, B., Koch, I., and Reimer, K. (2009). Bioremediation of diesel-contaminated soil by heated and humidified biopile system in cold climates. Cold Reg. Sci. Technol., 55, 167.

[72] Antizar-Ladislao, B., Lopez-Real, J., and Beck, A. J. (2005). In-vessel composting-bioremediation of aged coal tar soil: effect of temperature and soil/green waste amendment ratio. Environ. Int., 31, 173.

[73] Michel., F. C. Jr., Quensen, J., and Reddy, C. A. (2001). Bioremediation of a PCB-contaminated soil via composting. Compost Sci. Util., 9, 274.

[74] Khan, Z., and Anjaneyulu, Y. (2006). Bioremediation of contaminated soil and sediment by composting. Remediation J., 16, 109.

[75] Prasanna, D., Venkata Mohan, S., Purushotham Reddy, B., and Sarma, P. N. (2008). Bioremediation of anthracene contaminated soil in bio-slurry phase reactor operated in periodic discontinuous batch mode. J. Hazard. Mater., 153, 244.

[76] Johnsen, A. R., Wick, L. Y., and Harms, H. (2005). Principles of microbial PAHdegradation in soil. Environ. Pollut., 133, 71

[77] Gan, S., Lau, E. V., and Ng, H. K. (2009). Remediation of soils contaminated with polycyclic aromatic hydrocarbons (PAHs). J. Hazard. Mater., 172, 532.

[78] Ambrosoli, R., Petruzzelli, L., Minati, J. L., and Marsan, F. A. (2005). Anaerobic $\mathrm{PAH}$ degradation in soil by a mixed bacterial consortium under denitrifying conditions. Chemosphere, 60, 1231.

[79] Chang, B. V., Shiung, L. C., and Yuan, S. Y. (2002). Anaerobic biodegradation of polycyclic aromatic hydrocarbon in soil. Chemosphere, 48, 717.

[80] Sayara, T., Pognani, M., Sarra, M., and Sanchez, A. (2010). Anaerobic degradation of PAHs in soil: Impacts of concentration and amendment stability on the PAHs degradation and biogas production. Int. Biodeter. Biodegr., 64, 286.

[81] Ramakrishna, M., Venkata Mohan, S., Shailaja, S., Narashima, R., and Sarma, P. N. (2008). Identification of metabolites during biodegradation of pendimethalin in bioslurry reactor. J. Hazard. Mater., 151, 658.

[82] Venkata Mohan, S., Ramakrishna, M., Shailaja, S., and Sarma, P. N. (2007). Influence of soil-water ratio on the performance of slurry phase bioreactor treating herbicide contaminated soil. Bioresource Technol., 98, 2584.

[83] Soda, S., Kanzaki, M., Yamamuara, S., Kashiwa, M., Fujita, M., and Ike, M. (2009). Slurry bioreactor modeling using a dissimilatory arsenate-reducing bacterium for remediation of arsenic-contaminated soil. J. Biosci. Bioeng., 107, 130.

[84] United States Environmental Protection Agency EPAI540/R-94/521 (1998). TerraKleen Response Group, Inc. Solvent Extraction Technology-Innovative Technology Evaluation Report. Available at http://www.epa.gov/nscep/index.html (Accessed July 19, 2013).

[85] Collins, L. D., and Daugulis, A. J. (1999). Simultaneous biodegradation of benzene, toluene, and p-xylene in a two-phase partitioning bioreactor: concept demonstration and practical application. Biotechnol. Prog., 15, 74.

[86] Amsden, B. G., Bochanysz, J., and Daugulis, A. J. (2003). Degradation of xenobiotics in a partitioning bioreactor in which the partitioning phase is a polymer. Biotechnol. Bioeng., 84, 399.

[87] Prpich, G. P., Adams, R. L., and Daugulis, A. J. (2006). Ex situ bioremediation of phenol contaminated soil using polymer beads. Biotechnol. Lett., 28, 2027. 
[88] Rehmann, L., Prpich, G. P., and Daugulis, A. J. (2008). Bioremediation of PAH contaminated soils: Application of a solid-liquid two-phase partitioning bioreactor. Chemosphere, 73, 798.

[89] Organization for Economic Cooperation and Development. (1984). Earthworm, acute toxicity test. OECD Guideline for Testing Chemicals 207. Paris, France: OECD.

[90] Rehmann, R., and Daugulis, A. J. (2008). Biodegradation of PCBs in two-phase partitioning bioreactors following solid extraction from soil. Biotechnol. Bioeng., 99, 1273.

[91] Yeom, S. H., Daugulis, A. J., and Leeb, S. H. (2010). Bioremediation of phenolcontaminated water and soil using magnetic polymer beads. Process Biochem., 5, 1582.

[92] Robles-González, I., Rios-Leal, E., Sastre-Conde, I., Fava, F., Rinderknecht-Seijas, N., and Poggi-Varaldo, H. M. (2012). Slurry bioreactors with simultaneous electron acceptors for bioremediation of an agricultural soil polluted with lindane. Process Biochem., 47, 1640.

[93] Daugulis, A. J., and Janikowski, T. B. (2002). Scale-up performance of a partitioning bioreactor for the degradation of polyaromatic hydrocarbons by Sphingomonas aromaticivorans. Biotechnol. Lett., 24, 591.

[94] Prpich, G. P., Rehmann, L., and Daugulis, A. J. (2008). On the use, and reuse, of polymers for the treatment of hydrocarbon contaminated water via a solid-liquid partitioning bioreactor. Biotechnol. Prog., 24, 839.

[95] Pudge, I. B., Dubois, C., and Daugulis, A. J. (2003). The use of Enterobacter cloacae ATCC 43560 in the development of a two-phase partitioning bioreactor for the destruction of hexahydro-1,3,5-trinitro-1,3,5-s-triazine (RDX). J. Biotechnol., 100, 65 . 